\title{
ON THE MEANING THAT TEACHERS IN TRAINING WILL GIVE TO THE ACCURACY OF A CONFIDENCE INTERVAL AND ITS RELATIONSHIP WITH THE SAMPLE SIZE AND LEVEL OF CONFIDENCE
}

\author{
Gabriel Yáñez Canal, Luzdari Rangel Ruiz \\ Universidad Industrial de Santander, Colombia \\ gyanez@uis.edu.co
}

Confidence intervals, for their inferential nature, are useful when you want to estimate parameters of a population, based on the information provided by a random sample. One of the characteristics possessed by these elements is that they define the estimation error on a confidence interval - the sample size, population standard deviation (assuming that it is known), and the level of confidence - is its complete independence, in the sense that neither is conditioned by the value of the other two. However, in a study involving trainee teachers, who had studied the subject two years prior to the completion of this investigation, it was found that, when asked about the concept of accuracy in a confidence interval, some established wrong links between sample size and the level of confidence relationships, an example of this is to assume that increasing the sample size results is an increase in the level of confidence.

\section{INTRODUCTION}

Studies about confidence intervals have established the difficulties and the types of concepts that students, academics, experts and researchers teachers have, when faced with situations that require its construction and interpretation. Such types of conceptions refer to the association made between the size of an interval and its dependence on sample size and confidence level: the size of the interval is inversely proportional to the level of confidence and, in turn, the interval size is proportional to the sample size (Behar 2001; Fidler \& Cumming 2005; Olivo 2008; Yáñez \& Behar 2009; Chance \& McGaughey 2014). The difficulties are of conceptual nature, such as assuming that the values contained in a confidence interval are the possible values of the sample mean, and not the possible values of the population mean, and give a Bayesian interpretation of the confidence interval assuming that the confidence level is the posterior probability of obtaining the parameter within the range, once the sample is collected (Behar 2001; Olivo, Batanero \& Díaz 2008; Kalinowski 2010; Salcedo, Lira, González \& Yáñez, 2011).

In order to know the reasons that can lead to these misconceptions, a study was conducted with mathematics teachers in training, aimed to describe the mental structures and mechanisms involved with the construction of the concept of confidence interval. In this research it was assumed as a theoretical reference the APOS Theory (Action, Process, Object and Scheme), which takes into account the mental structures and mechanisms that an individual develops when learning a mathematical concept.

The study focused on building a confidence interval for the population mean, with known standard deviation. The algebraic expression that leads to the estimation of a confidence interval is as follows:

$$
\bar{X} \pm Z_{1-\alpha / 2} \frac{\sigma}{\sqrt{n}}
$$

Where $\bar{X}$ is the sample mean, $Z_{1-\alpha / 2}$ is the percentile of the standard normal associated with the level of confidence and $\frac{\sigma}{\sqrt{n}}$ is the standard deviation, or estimated error, associated with the random variable $\bar{X}$.

While research covers various aspects, in this article we will just present some evidence which allows us to identify the concept of confidence interval accuracy that some students have, and the relationship established between the sample size and the level of confidence of the confidence intervals.

Below we briefly present the methodology used in this research and the excerpts from interviews with students who participated in the research. 


\section{METHODOLOGY}

The research included two phases: 1. Theoretical analysis about confidence intervals, design and implementation of a questionnaire, which besides ratifying the concepts mentioned previously, it also allowed us to identify others, and establish hypothetical reasons that support them. 2. Design and conduct didactical interviews to better understand the mental structures and mechanisms that students developed around confidence intervals.

\section{RESULTS}

Here we present some results related to the sample size and the level of confidence. We show some of the items proposed in the questionnaire, its answers, (written and oral) given by students and the reasons behind them.

Item 2: If the sample size is increased, keeping the other constant data, the confidence interval becomes wider. Answer True or False and justify your answer (Item proposed by Behar 2001)

Figure 1. Response of a student to item 2.

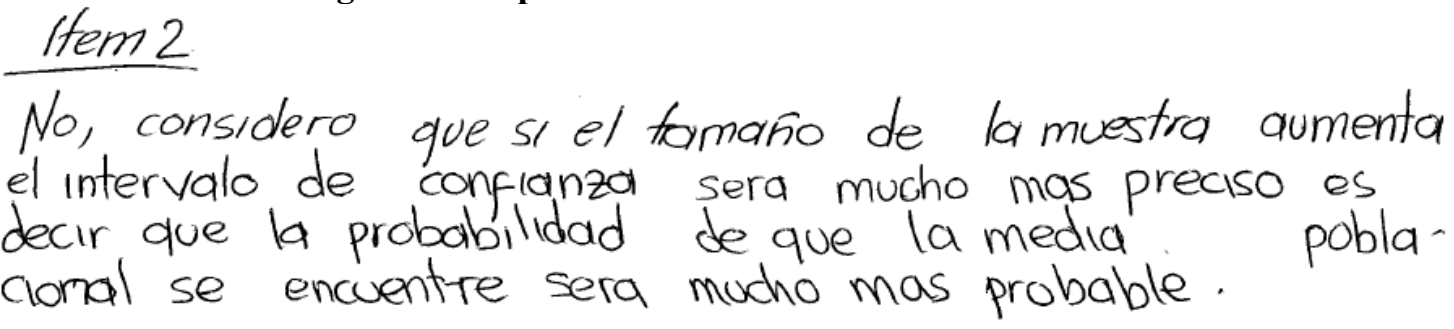

Item 2. No, I think that if the sample size increases the confidence interval will be much more precise, the probability that the population mean is found will be much more likely.

In Figure 1, we observe the association that the student establishes between sample size and precision of the interval. As shown, the student takes the precision of the interval in terms of the probability that the interval contains the mean population. Its train of thought is constructed as follows: the sample size is directly related to the precision of the interval, which in turn identifies the probability that the interval contains the population mean. If we remember that both in this study, and in many others also made on confidence intervals, participants associated the level of confidence with the probability that the interval contains the population mean, we can say that the student established the following relationship: "by increase the sample size, the confidence level is increased."

Item 3: If the confidence level is increased, keeping the other data constant, the confidence interval becomes narrower. Answer True or False and justify your answer (Behar, 2001).

Figure 2. Response of a student to Item 3.

$$
\begin{aligned}
& \text { 3] Verdadero, porqu en este caso se vá a tener mayor precisión } \\
& \text { en el estudio qu se hace y el evror va a cer menor. }
\end{aligned}
$$

3) True because in this case the study done will be more accurate and the error will be smaller.

In this case the student takes a directly proportional association between the level of confidence and precision of the interval.

To improve the clarity on the interpretation that students give to the concept of precision, the following items related to the sample size and the confidence level is as proposed.

Item 7: Increasing the sample size increases the accuracy of the estimate of the population mean. Answer True or False and justify your answer 
This item was proposed considering that, hypothetically, we had assumed that the reason for misunderstanding the effect on the size of the interval in the sample size is based on a purely intuitive association, "to more data, more accurate estimation and bigger the interval; therefore, the precision is interpreted in terms of confidence to get the parameter value in the range built, as if the confidence level depended, in turn, on the sample size, which leads to increase the size of the interval.

Most students $(12 ; 80 \%)$ assumed as true the statement of item 7 , their arguments based mainly on the law of large numbers and Central Limit Theorem.

Figure 3. Student Response to Item 7.

$$
\begin{aligned}
& \text { Ítan 7. (videdero) entre mós grande sa el tomoño de lo mestra }
\end{aligned}
$$

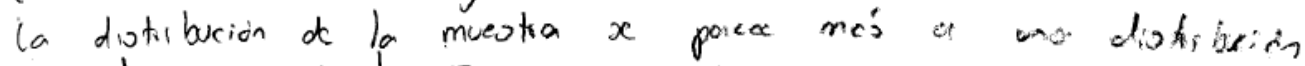

$$
\begin{aligned}
& \text { namal } y \text { per tonto } \bar{x} \text { ua ar mos aproximodo a } \mu \text {. El to se } \\
& \text { tice por el Tma cartial }
\end{aligned}
$$

(True) the larger the sample size, the distribution of the sample is more likely to have a normal distribution and therefore $\bar{x}$ will be closer to $\mu$. This is the Central Limit Theorem.

This conclusive answer highlights the importance of knowing how to interpret the Central Limit Theorem (CLT) prior to the construction of the confidence interval. Although the trainee teacher does not imply it, one might think that the approximation of $\bar{x}$ to $\mu$, as the sample size increases, is the result of shrinking the standard deviation of the distribution: $\sigma / \sqrt{\mathrm{n}}$

Item 8: If you increase the confidence level, the accuracy of the estimate of the population mean also increases. Answer True or False and justify your answer.

Most students $(11 ; 73.4 \%)$ associated the accuracy with level of confidence, a greater level of confidence, gives greater accuracy.

Figure 4. Response of a student to Item 8.

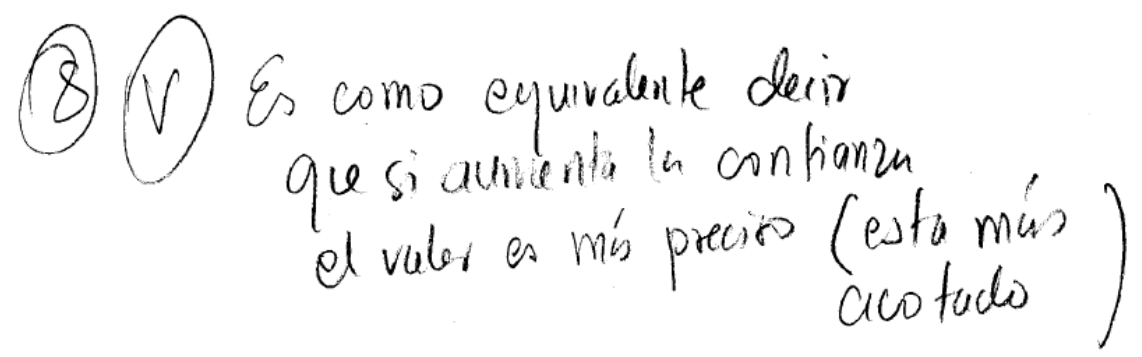

It is equivalent to say that if you increase the confidence, the value is more accurate (it is more limited)

As suspected, some students equate the level of confidence with precision: "It's like equivalent". The Figures 4 and 5 realize this concept that goes against the meaning of the confidence level.

Figure 5. Response of a student to Item 8.

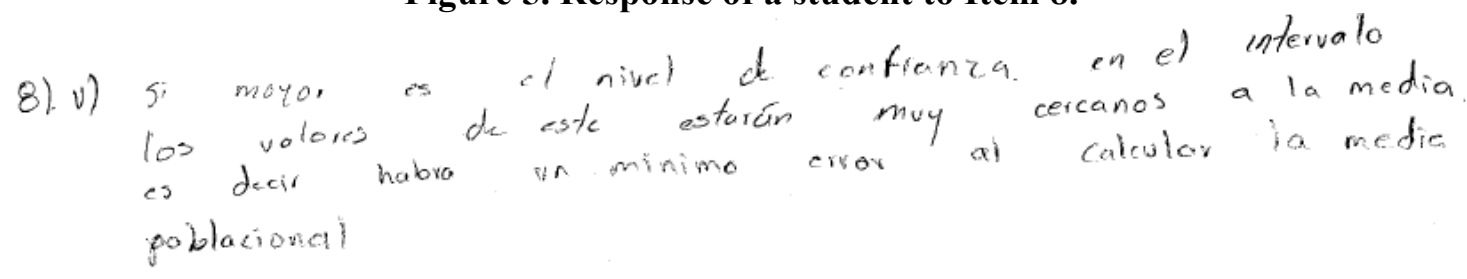

If the confidence level is higher in the range, its values will be very close to the mean, therefore, there will be a minimum error in calculating the population mean. 
Following the completion of the diagnostic test, some students were selected, to undergo interviews of academic nature, with the aim to know in depth the reasons for their answers. Below are shown and discuss some of the answers given by some students about the alleged relationship between sample size and confidence level.

Interviewer (I): The following statement is true or false? Increasing the sample size increases the accuracy of the estimate of the population mean.

Maria (M): Ehhh, it is true... Well yes, it is true, but it seems as obvious.

E: What is accuracy for you? What does it mean estimation accuracy?

M: That it will be more accurate, more precise, and more accurate. The mean, $\bar{x}$ will be more approximated to $\mu$.

E: So, accuracy increases as the sample size increases?

M: Yes, but I think that depends on whether the data is random. Starting from the fact that it is. Then yes.

E: And why?

M: Because yes (laughs)

$E$ : In terms of confidence intervals, how ensure that the sample mean is closer to $\mu$ ?

M: (Look what you have written on the board) because, if I, if I increase the sample too much then the range will be much larger.

Figure 6. Sketches of María

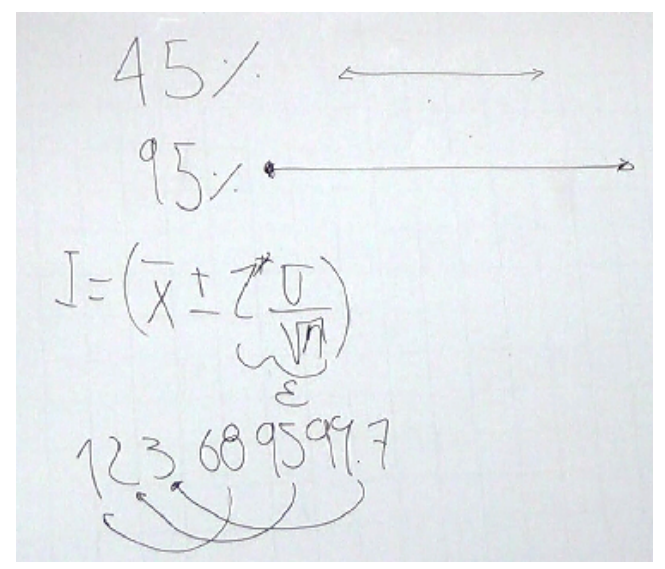

E: if I increase the confidence level, it increases the accuracy of the estimator?

$M:$ (is left wondering)

E: If there is more confidence, then is there more accuracy?

M: As far as accuracy, I think not, because ... because let's say that I can ensure that my test score will be, will be, let's say, 3 roughly 2, and I can do it with a confidence level of $99 \%$.

E: So if I increase the confidence level, this increases the accuracy of the estimate?

M: Well, I'm confused because let's say, for a range of 45\% confidence, I got this (points to the first interval has drawn on the board, see Figure 6) and for 95\% I got this (points to the second interval, see Figure 6)

Then 95\% means that for every 100 intervals the $\mu$ will be in 95 of these intervals.

$E: O k$

M: So, it's going to be as accurate because the range will be bigger.

E: You can guarantee that it will be in more intervals, therefore at $95 \%$ I can say that it will be in 95 out of 100 and at 45\% I can say that it will be in 45 out of 100.

M: Well... yes.

E: So which one is more accurate?

M: The 95\% 
Although initially Mary says that increasing the sample size is reflected in the increased precision of the interval by saying, "... the mean, $\bar{x}$ will be closer to $\mu$ ", she later contradicts herself saying that "If I increase the sample too much then the range will be much bigger." María has two different and contradictory interpretations to the concept of the precision of an interval, which she does not stop to solve, even though she was the only student who could remember the exact expression that defines a confidence interval. On one hand, she associated it with the proximity of the desired parameter estimator and, on the other hand, associated it with a larger set of possibilities, in which case, the results increased the size of the interval. The latter interpretation appears again when she explicitly says "it will be more accurate because the range is going to be bigger."

When asked about the effect on the accuracy that the size of the confidence level has, Maria resorted to a proper interpretation of the confidence level, which shows that by increasing the confidence level it increases the accuracy of the range, since repeating the procedure 100 times ensures that there will be more intervals containing the desired parameter when the confidence level is higher. With this, Mary has another interpretation for the accuracy of the confidence interval: the probability that the interval contains the parameter.
Interviewer (I): If the sample size is increased, keeping the other data constant, the confidence interval becomes wider.
Santiago (S): No, I think ... that remains the same, I mean, after a certain point it is maintained.
E: So your contention is that if the sample size is increased, there comes a time when it has no effect on the width of the confidence interval.
S: Yes
E: But before we get to that point, if I increased the sample size by little what about the size of the interval, it grows or does not grows?
S: Hmmm, I think it becomes narrower.
E: Why?
S: Because ... because if the size grows, it will have more ... less certainty of what they would be working, because as I increase the sample, the main purpose is that the sample gets more closer to the population. Then as the sample gets closer to the people, the value taken by the sample mean should be brought closer to the population. Then as it comes closer, I have the idea of limit in the real numbers so to speak, then the interval becomes smaller. Rather, what I am saying is that ... (is left wondering) if I think when people approach to the expected number, yes, I think it will not change much, the idea is that the interval becomes more compact, smaller.

In the dialogue with Santiago we can see that he does not try to answer the question within the confidence intervals, but from a process of approximation between the punctual estimator $\bar{x}$ and the parameter to estimate $\mu$. He also assumes a finite population and applies a valid intuitive reasoning: by increasing the sample, it is more like the population; therefore the average of the sample should be very similar to the average population.

\section{CONCLUSIONS}

The responses illustrated show different conceptions of the concept of precision in a confidence interval: Such as, the accuracy of a confidence interval is the probability that this interval contains the parameter to be estimated; a confidence interval is more accurate to the extent that $\bar{x}$ is closer to $\mu$ and the more data containing the confidence interval, the more accurate it is. Closely related to these conceptions about the accuracy of interval, it is evident a relation hitherto not described in the literature, between sample size and the level of confidence: "larger sample size means greater accuracy in the estimation and therefore the probability that the interval contains the population mean is greater ", hence, by increasing the sample size, there is a large number of values that are within the range, which necessarily increase of the size of the interval and thus, the probability that this interval contains the parameter, is greater. The conclusion is given considering 
that the trainee teachers assume the level of confidence as the probability that the interval contains the parameter being estimated.

\section{REFERENCES}

Arnon, I., Dubinsky, E., Cottrill, J., Oktaç, A., Roa-Fuentes, S., Trigueros, M. \& Weller, K. (2013). Apos theory - a framework for research and curriculum development in mathematics education. New York: Springer.

Behar, R. (2001). Aportaciones para la mejora del proceso de enseñanza aprendizaje de la estadística. Tesis doctoral no publicada. Universidad Politécnica de Catalunya. Barcelona, España.

Behar, R., \& Yáñez, G. (2009). Experts and students' conceptions regarding confidence intervals. Heurística, 16, 5-12

Chance, B., \& McGaughey, K. (2014). Impact of a simulation/randomization based curriculum on student understanding of p-values and confidence intervals. In K. Makar, B. de Sousa, \& R. Gould (Eds.), Sustainability in statistics education. Proceedings of the Ninth International Conference on Teaching Statistics (ICOTS9), Flagstaff, Arizona, USA. Voorburg, The Netherlands: International Statistical Institute.

Cumming, G., \& Fidler, F. (2005). Interval estimates for statistical communication: problems and possible solutions. In A. Rossman y B. Chance (Eds.). Satellite Conference on Statistics Education and the Communication of Statistics (IASE). Sydney, Australia.

Kalinowski, P. (2010) Identifying misconceptions about confidence intervals. In C. Reading (Ed.), Data and context in statistics education: Towards an evidence-based society. Proceedings of the Eighth International Conference on Teaching Statistics (ICOTS8, July, 2010), Ljubljana, Slovenia. Voorburg.

Olivo, E. (2008). Significado de los intervalos de confianza para los estudiantes de ingeniería en México. Tesis doctoral no publicada. Universidad de Granada, España.

Olivo, E., Batanero, C., \& Díaz, C. (2008). Dificultades de comprensión del intervalo de confianza en estudiantes universitarios. Educación Matemática, 20(3), 5-32.

Salcedo, A., Lira, B., González, J., \& Yáñez, G. (2011). Interpretación de intervalos de confianza por docentes en formación. En Blanco, E. (Comp), Investigación Educativa: Venezuela en Latinoamérica Siglo XXI (pp. 209-229), Venezuela: Centro de Investigaciones Educativas (CIES).

Yáñez, G., \& Behar, R. (2009). Interpretaciones erradas del nivel de confianza en los intervalos de confianza y algunas explicaciones plausibles. En M. J. González; M. T. González y J. Murillo (Eds.), Investigación en Educación Matemática. Comunicaciones de los grupos de investigación. XIII Simposio de la SEIEM. Santander. 